\title{
Structural Analysis of a Polysaccharide Isolated from the Alkali Extract of an Edible Mushroom, Pleurotus sajor-caju, Cultivar Black Japan
}

\author{
A. K. Ojha* \\ Department of Chemistry, Mahishadal Girls' College, Mahishadal, Purba Medinipur, West Bengal, India
}

Received 19 May 2021, accepted in final revised form 23 July 2021

\begin{abstract}
A heteropolysaccharide (PS-I) and an insoluble glucan (PS-II) were isolated from the alkaline extract of an edible mushroom Pleurotus sajor-caju, cultivar Black Japan. The polysaccharide (PS-I) was found to consist of D-glucose and D-galactose in a molar ratio of 3:1. Based on total acid hydrolysis, methylation analysis, and NMR experiments $\left({ }^{1} \mathrm{H},{ }^{13} \mathrm{C}\right.$, DQF-COSY, TOCSY, NOESY, ROESY, HMQC, and HMBC), the structure of the repeating unit of the polysaccharide was established as

PS-I: $\rightarrow 6)-\alpha-D-G l c p-(1 \rightarrow 3)-\beta-D-G l c p-(1 \rightarrow 6)-\beta-D-G l c p-(1 \rightarrow$

6

$\uparrow$

1

$\alpha-\mathrm{D}-\mathrm{Gal} p$

This polysaccharide possesses macrophage activity on mouse monocyte cell lines. The structure of the insoluble glucan was established as

PS-II: $\rightarrow 3)-\beta-D-G l c p-(1 \rightarrow$

Keywords: Pleurotus sajor-caju; Cultivar Black Japan; Mushroom polysaccharide; Structure; NMR spectroscopy.

(C) 2021 JSR Publications. ISSN: 2070-0237 (Print); 2070-0245 (Online). All rights reserved. doi: http://dx.doi.org/10.3329/jsr.v13i3.53502

J. Sci. Res. 13 (3), 1025-1041 (2021)
\end{abstract}

\section{Introduction}

Among different types of mushrooms of the genus Pleurotus, namely Pleurotus sajor-caju [1-4] Pleurotus ostreatus [5,6], Pleurotus citrinopileatus [7], and Pleurotus florida [8-14] are reported as commonly available edible mushrooms having immunostimulating and antitumor materials. These are also known as oyster mushrooms or abalone mushrooms. Pleurotus sajor-caju [2] is a delicious edible fungus, first found by an Indian, Yan Dai ke, at the foot of the Himalayas and then distributed to many other countries throughout the world. Currently, it is cultivated all over the world. Pleurotus species (Oyster mushrooms) are commercially important edible mushrooms and cultivated globally [15]. Globally, Pleurotus mushrooms alone are cultivated around $25 \%$ of that total cultivated mushroom [16]. Pleurotus mushrooms are consumed as a functional food, attractive taste and aroma,

\footnotetext{
*Corresponding author: arnab.ojha@yahoo.com
} 
and nutritional and medicinal value. The oyster mushroom basidiocarps are shell or oyster shaped with different colors like white, cream, gray, yellow, pink, or light brown. In Asia, the widely used substrates for the cultivation of this mushrooms species are rice straw and cotton wastes [17]. This mushroom contains [2] very little lipid or starch but some protein also. The FAO report showed that the Pleurotus species contain $30.4 \%$ protein [18]. Due to high proteins, fiber, vitamins, and minerals, Pleurotus mushrooms are considered healthy. The Pleurotus mushrooms are a good source of zinc, contributing to the cause of human nutrition. Iron content in Pleurotus species has been reported in the range of 5.513.4. The aqueous extract contains vitamins $\mathrm{B}_{1}, \mathrm{~B}_{2}$, and $\mathrm{C}$, reducing the cholesterol level in the blood. Thus, it is considered a vital health tonic. Extracellular polysaccharides obtained from the liquid culture medium of the mycelium of P. sajor-caju have been reported [19]. It was shown that extracellular polysaccharides, polysaccharide, exopolysaccharides and mycelial polysaccharides of sajor-caju origin have antiproliferative and antitumor effects on HeLa cells, Hep-2 cells lines and sarcoma 180 of mice [20]. P. sajor-caju was found effective in the degradation of the pesticides, p,pDDT and lindane [21]. Again, silver NPs are synthesized by Pleurotus sajor-caju, and these NPs showed antifungal effects against Candida albicans [22]. Recently, silver - gold NPs are synthesized from Pleurotus sajor-caju, and it was affected against colon cancer cell lines [23]. Some polysaccharides have been isolated from the fruit bodies of this mushroom using different solvents, and an antitumor [2] polysaccharide has been reported.

A cultivar of $P$. sajor-caju called Black Japan is commercially available on a large scale near Midnapore city during December-January. The main objective of this work is to investigate any difference in the constituent of polysaccharide of this variety from the original mushroom $P$. sajor-caju. The hot water extract of the edible mushroom $P$. sajorсаju was found to consist of two fractions and identified as glucan [24] (Fr. I) and heteroglycan [25] (Fr. II), consisting of D-mannose, D-glucose, and D-galactose in equimolar ratio and reported in Carbohydrate Research. The aqueous extract of this variety (Black Japan) was found to consist of D-glucose and D-galactose in a molar ratio of 3:1 and reported in Carbohydrate Research. Two different polysaccharides were isolated from the alkaline extract of these fruit bodies: water-soluble (PS-I) and waterinsoluble (PS-II), respectively. The structural difference of the glucan (PS-I) with the previously reported one from P. sajor-caju (cv Black Japan) [26] is that the present polysaccharide contained $(1 \rightarrow 3,6)$-linked glucose not $(1 \rightarrow 4,6)$-linked i.e., one sugar linking is different, though both polysaccharides consist of D-glucose and D-galactose in a molar ratio of 3:1 and also this polysaccharide is biologically active.

\section{Experimental}

\subsection{Isolation and purification of the polysaccharide}

Fruit bodies of the mushroom, Pleurotus sajor-caju, cultivar Black Japan (1.0 kg) were collected from the local farm and washed with water. It was crushed and boiled in $500 \mathrm{~mL}$ 
of distilled water for $8 \mathrm{~h}$. The whole mixture was kept overnight at $4{ }^{\circ} \mathrm{C}$ and then filtered through a linen cloth. The filtrate was centrifuged at $8000 \mathrm{rpm}$ (using a Heraeus Biofuge Stratos centrifuge) for $45 \mathrm{~min}$ at $4{ }^{\circ} \mathrm{C}$. The supernatant was collected and precipitated in ethanol $(1: 5, \mathrm{v} / \mathrm{v})$. It was kept overnight at $4{ }^{\circ} \mathrm{C}$ and again centrifuged as above. The precipitated material (polysaccharide) was washed with ethanol four times and then froze dried. The freeze-dried material was dissolved in $30 \mathrm{~mL}$ of distilled water and dialyzed through dialysis tubing cellulose membrane (Sigma-Aldrich, retaining $>$ MW 12,400) against distilled water for $4 \mathrm{~h}$ to remove low molecular weight materials. The aqueous solution was then collected from the dialysis bag and freeze-dried to yield crude polysaccharide (wt. $1.2 \mathrm{~g}$ ).

The crude polysaccharide $(30 \mathrm{mg}$ ) was purified by gel permeation chromatography on column $(90 \times 2.1 \mathrm{~cm})$ of Sepharose $6 \mathrm{~B}$ in water as eluant $\left(0.4 \mathrm{~mL} \mathrm{~min}^{-1}\right)$ using Redifrac fraction collector. 95 test tubes $(2 \mathrm{~mL}$ each) were collected and monitored spectrophotometrically at $490 \mathrm{~nm}$ with phenol-sulfuric acid reagent [27] using Shimadzu UV-VIS spectrophotometer, model-1601. One homogeneous fraction (test tubes 28-58) was collected and freeze-dried, yielding $22 \mathrm{mg}$ of material. The purification process was carried out in seven lots, and polysaccharide fraction was again purified and collected (yield $150 \mathrm{mg}$ ).

\subsection{Monosaccharide analysis}

The polysaccharide sample $(3.0 \mathrm{mg})$ was hydrolyzed with $2 \mathrm{M} \mathrm{CF}_{3} \mathrm{COOH}(2 \mathrm{~mL})$ in a round-bottom flask at $100{ }^{\circ} \mathrm{C}$ for $18 \mathrm{~h}$ in a boiling water bath. The excess acid was completely removed by co-distillation with water. Then the hydrolyzed product was reduced with $\mathrm{NaBH}_{4}(9 \mathrm{mg})$, followed by acidification with dilute $\mathrm{CH}_{3} \mathrm{COOH}$, and then co-distilled with pure $\mathrm{CH}_{3} \mathrm{OH}$ to remove excess boric acid. The reduced sugars (alditol) were acetylated with 1:1 pyridine-acetic anhydride in a boiling water bath for $1 \mathrm{~h}$ to give the alditol acetates, which were analyzed by GLC and GLC-MS performed on HewlettPackard 5970A automatic GLC-MS system, using an HP-5 capillary column $(25 \mathrm{~m} \times 25$ $\mathrm{m})$. The program was isothermal at $150{ }^{\circ} \mathrm{C}$; hold time $2 \mathrm{~min}$, with a temperature gradient of $4{ }^{\circ} \mathrm{C} \min ^{-1}$ up to a final temperature of $200{ }^{\circ} \mathrm{C}$. Quantitation was carried out from the peak area, using response factors from standard monosaccharides.

\subsection{Methylation analysis}

The Polysaccharide (4.0 mg) was methylated using Ciucanu and Kerek method [28]. The methylated products were isolated by partition between $\mathrm{CHCl}_{3}$ and $\mathrm{H}_{2} \mathrm{O}(5: 2$, v/v). The organic layer containing products was washed with $3 \mathrm{~mL}$ water three times and dried. The methylated products were then formalized with $90 \%$ formic acid $(1 \mathrm{~mL})$ at $100{ }^{\circ} \mathrm{C}$ for 1 $\mathrm{h}$, reduced with sodium borohydride, acetylated with (1:1) acetic anhydride-pyridine, and analyzed by GLC-MS (using HP-5 fused silica capillary column) and the same temperature program indicated above. 


\subsection{Periodate oxidation}

The Polysaccharide $(5 \mathrm{mg})$ was oxidized with $0.1 \mathrm{M}$ sodium meta periodate $(2 \mathrm{~mL})$ at 27 ${ }^{\circ} \mathrm{C}$ in the dark for $48 \mathrm{~h}$. The excess periodate was destroyed by adding 1, 2-ethanediol, and the solution was dialyzed against distilled water. The dialyzed material was reduced with $\mathrm{NaBH}_{4}$ for $15 \mathrm{~h}$ and neutralized with acetic acid. The resulting material was obtained by co-distillation with methanol. The periodate reduced material was divided into two portions. One portion was hydrolyzed with $2 \mathrm{M} \mathrm{CF}_{3} \mathrm{COOH}$ for $18 \mathrm{~h}$, and alditol acetate was prepared as usual. Another portion was methylated by Ciucanu and Kerek method, and alditol acetate of this methylated product was prepared.

\subsection{Absolute configuration of monosaccharides}

This method used was based on Gerwig et al. [29]. The polysaccharide (1.0 mg) was hydrolyzed with $\mathrm{CF}_{3} \mathrm{COOH}$, and then the acid was removed. A solution of $250 \mu \mathrm{L}$ of 0.625 (M) $\mathrm{HCl}$ in $\mathrm{R}-(+)-2$-butanol was added and heated at $80{ }^{\circ} \mathrm{C}$ for $16 \mathrm{~h}$. Then the reactants were evaporated, and TMSi-derivatives were prepared with NO-bis (trimethylsilyl) trifluroacetamide (BSTFA). The products were analyzed by GLC using a capillary column SPB-1 $(30 \mathrm{~m} \times 0.26 \mathrm{~mm})$, a temperature program $\left(3{ }^{\circ} \mathrm{C} / \mathrm{min}\right)$ from 150 to $210{ }^{\circ} \mathrm{C}$. The 2,3,4,6-tetra- $O$-trimethylsilyl-(+)-2-butyl glycosides obtained were identified by comparing those prepared from the $\mathrm{D}$ and $\mathrm{L}$ enantiomers of different monosaccharides.

\subsection{Optical rotation}

Optical rotation was measured by a Jasco Polarimeter model P-1020 at $25^{\circ} \mathrm{C}$.

\subsection{Determination of molecular weight [30]}

The molecular weight of polysaccharides was determined by gel-chromatographic technique. Standard dextrans T-200, T-70, and T-40 were passed through a sepharose 6B column, and then the elution volumes were plotted against the logarithms of their respective molecular weights. The elution volume of polysaccharide was then plotted in the same graph, and the molecular weight of polysaccharide was determined.

\subsection{NMR studies}

${ }^{1} \mathrm{H}$ NMR and ${ }^{13} \mathrm{C}$ NMR experiments were performed with Bruker Avance DPX-500 spectrometer at $27{ }^{\circ} \mathrm{C}$. The polysaccharide was dried over $\mathrm{P}_{2} \mathrm{O}_{5}$ in a vacuum for several days, and then deuterium was exchanged [31] four times, followed by lyophilizing with $\mathrm{D}_{2} \mathrm{O}$ (99.96\% atom ${ }^{2} \mathrm{H}$, Aldrich). The ${ }^{1} \mathrm{H}$ NMR spectrum was recorded by suppressing the HOD signal (fixed at $\delta 4.67 \mathrm{ppm}$ ) using the WEFT pulse sequence [32]. The 2D-DQFCOSY experiment was carried out using standard Bruker software at $27^{\circ} \mathrm{C}$. The TOCSY 
experiment was recorded at a mixing time of $300 \mathrm{~ms}$, and the complete assignment required several TOCSY experiments having mixing times ranging from 60 to $300 \mathrm{~ms}$. The NOESY and ROESY mixing delays were $300 \mathrm{~ms}$. The ${ }^{13} \mathrm{C}$ NMR spectrum of polysaccharide, solution in $\mathrm{D}_{2} \mathrm{O}$ was recorded at $27^{\circ} \mathrm{C}$ using acetone as internal standard, fixing the methyl carbon signal at $\delta 31.05 \mathrm{ppm}$. The delay time in the HMBC experiment was $80 \mathrm{~ms}$.

\subsection{GLC experiments}

All gas-liquid chromatography was performed on a Hewlett-Packard Model 5730 A gas chromatograph having a flame ionization detector and glass columns $(1.8 \mathrm{~m} \times 6 \mathrm{~mm})$ packed with $3 \%$ ECNSS-M (A) on Gas Chrom Q (100-120 mesh) and 1\% OV-225 (B) on Gas Chrom Q (100-120) mesh). All GLC analyses were performed at $170{ }^{\circ} \mathrm{C}$.

\subsection{GLC-MS experiments}

All the GLC-MS experiments were carried out in a Hewlett-Packard 5970 MSD instrument using HP-5 fused silica capillary column. The program was isothermal at 150 ${ }^{\circ} \mathrm{C}$; hold time $2 \mathrm{~min}$, with a temperature gradient of $4{ }^{\circ} \mathrm{C} \mathrm{min}^{-1}$ up to a final temperature of $200{ }^{\circ} \mathrm{C}$.

\subsection{Test for macrophage activity by Nitric oxide assay}

Peritoneal macrophages (concentration $5 \times 10^{5}$ cells $\mathrm{mL}^{-1}$ ) cells are growing in complete RPMI (Roswell Park Memorial Institute) media in 96-well flat-bottom tissue culture plate $[33,34]$. After the cells were left overnight for attachment, they were treated with different concentrations of polysaccharides. The cells were cultured for $24 \mathrm{~h}$ at $37{ }^{\circ} \mathrm{C}$ in a humidified $5 \% \mathrm{CO}_{2}$ incubator. Production of nitric oxide was estimated by measuring nitrite levels in cell supernatant with Greiss reaction [35]. Equal volumes of Greiss reagent (1:1 of $0.1 \%$ in 1-naphthyl ethylenediamine in $5 \%$ phosphoric acid and $1 \%$ sulfanilamide in $5 \%$ phosphoric acid) and sample cell supernatant were incubated together at room temperature for $10 \mathrm{~min}$. Absorbance was observed at $550 \mathrm{~nm}$.

\subsection{Splenocyte and Thymocyte Proliferation Assay [36-39]}

A single-cell suspension of the thymus and spleen was prepared by homogenization in Hank's balanced salt solution (HBSS) under aseptic conditions from normal mice. The suspension was centrifuged to obtain cell pellets. The contaminant RBC was removed using hemolytic Gey's solution. The cells were resuspended in a complete RPMI medium after two washes in HBSS. After washing two times in PBS the cells were resuspended in a complete RPMI medium. Cell concentration was adjusted to $1 \times 10^{5}$ cells $/ \mathrm{mL}$, and viability of the suspended cells (as tested by trypan blue dye exclusion) was always over $90 \%$. The cells $(180 \mu \mathrm{L})$ were plated in 96- well flat-bottom plates and incubated with 20 
$\mu \mathrm{L}$ of various concentrations (10 to $100 \mu \mathrm{g} / \mathrm{mL})$ of the polysaccharide. Lipopolysaccharide (LPS) of $4 \mu \mathrm{g} / \mathrm{mL}$ was used as a positive control. Cultures were set up for $72 \mathrm{~h}$ at $37{ }^{\circ} \mathrm{C}$ in a humidified atmosphere of $5 \% \mathrm{CO}_{2}$. Proliferation was checked by MTT assay method. Data were reported as the mean \pm standard deviation of six different observations and compared against PBS control.

\section{Result and Discussion}

\subsection{Characterization of PS-1}

Two different crude polysaccharides were isolated from the sun-dry mushroom, Pleurotus sajor-caju cv. Black Japan $(2.0 \mathrm{Kg})$ by hot alkaline $(4 \% \mathrm{NaOH})$ extraction, followed by precipitation in $\mathrm{EtOH}(1: 5, \mathrm{v} / \mathrm{v})$ and centrifugation. The whole mixture was kept overnight at $4^{\circ} \mathrm{C}$ and then filtered through a linen cloth. The filtrate was centrifuged at $8000 \mathrm{rpm}$ (using a Heraeus Biofuge Stratos centrifuge) for $45 \mathrm{~min}$ at $4{ }^{\circ} \mathrm{C}$. The supernatant was collected and precipitated in ethanol $(1: 5, \mathrm{v} / \mathrm{v})$. It was kept overnight at $4{ }^{\circ} \mathrm{C}$ and again centrifuged as above. The precipitated material (polysaccharide) was washed with ethanol four times and then froze dried. The freeze-dried material was dissolved in $30 \mathrm{~mL}$ of distilled water and dialyzed through dialysis tubing cellulose membrane against distilled water for $4 \mathrm{~h}$ to remove low molecular weight materials. The aqueous solution was then collected from the dialysis bag and freeze-dried to yield crude polysaccharide (wt. $1.2 \mathrm{~g}$ ).

The crude polysaccharide ( $30 \mathrm{mg}$ ) was purified by gel permeation chromatography on a column of Sepharose $6 \mathrm{~B}$ in water as eluant. Ninety-five test tubes $(2 \mathrm{~mL}$ each) were collected and monitored spectrophotometrically at $490 \mathrm{~nm}$ with the phenol-sulfuric acid reagent. When the absorbance was plotted against the elution volume, a graph (Fig. 1) containing one peak corresponding to one homogeneous polysaccharide fraction (BJPS, $22 \mathrm{mg}$ ) was obtained.

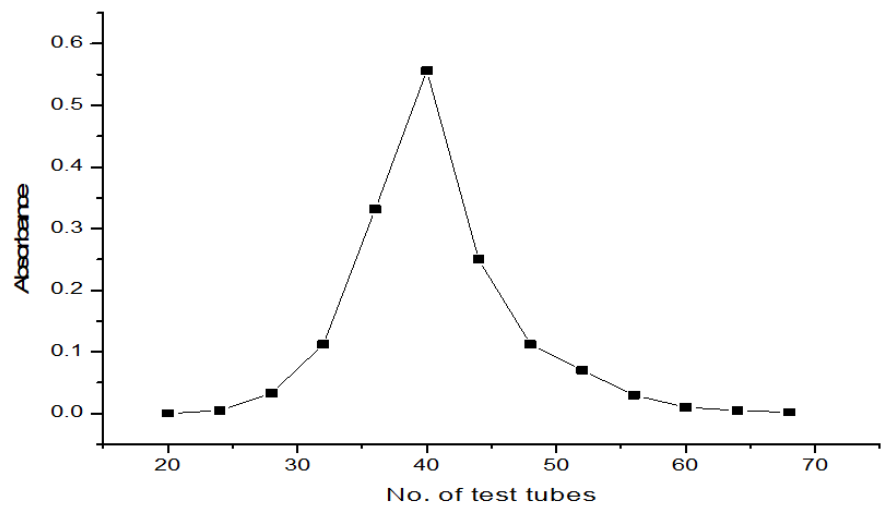

Fig. 1. Gel permeation chromatogram of the water-soluble polysaccharide isolated from P. sajorcaju (cv Black Japan) using Sepharose 6B column at a flow rate of 10 drops $/ \mathrm{min}$. 
The polysaccharide showed a specific rotation of $[\alpha]_{D}{ }^{25}+24.0$ (c 0.80 , water). The molecular weight of this polysaccharide was estimated (Fig. 2) from a calibration curve prepared with standard dextrans [23] as $\sim 2.8 \times 10^{4}$ Da.

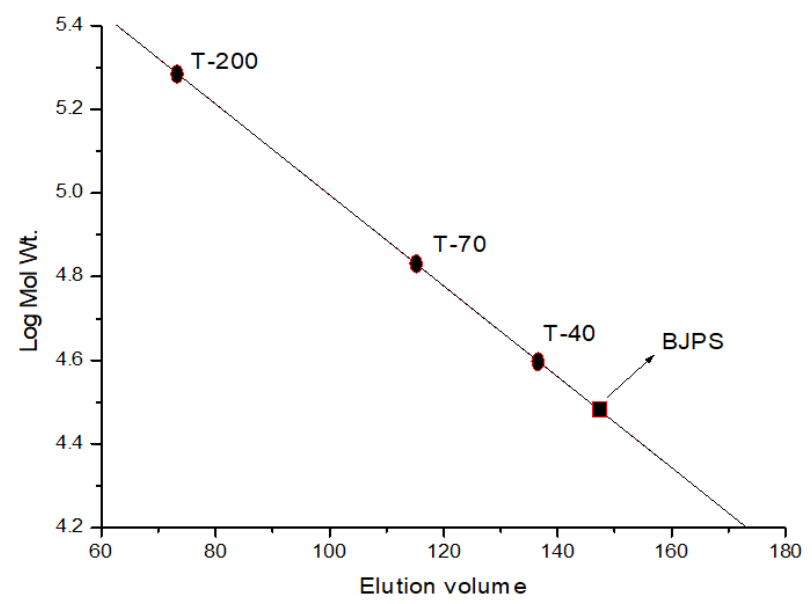

Fig. 2. Determination of molecular weight of the polysaccharide isolated from P. sajor-caju (cv Black Japan) by gel permeation chromatography in Sepharose 6B column.

The polysaccharide (PS-I) on acid hydrolysis by 2M TFA showed D-glucose and Dgalactose detected by GLC analysis and found to be present in a molar ratio of 3:1, respectively. The total carbohydrate of this fraction was estimated to be $97.6 \%$ using the phenol-sulfuric acid method [27]. The absolute configuration [29] of each monosaccharide was determined by GLC examination of 2,3,4,6-tetra- $O$-trimethylsilyl(+)-2-butyl glycosides and showed that all have the D configuration. The mode of linkages of the polysaccharide was determined by methylation analysis using the method of Ciucanu and Kerek [28], followed by formolysis and alditol acetate preparation. The alditol acetates were then analyzed through GLC as well as by GLC-MS using an HP-5 fused silica capillary column and the presence of 1,5,6-tri- $O$-acetyl-2,3,4-tri- $O$-methyl-Dglucitol; 1,3,5,6-tetra- $O$-acetyl-2,4-di- $O$-methyl-D-glucitol; and 1,5-di- $O$-acetyl-2,3,4,6tetra- $O$-methyl-D-galactitol in a molar ratio of 2:1:1 were detected. These results indicate that $(1 \rightarrow 6)$-linked D-glucopyranosyl, $(1 \rightarrow 3,6)$-linked D-glucopyranosyl moieties, and terminal D-galactopyranosyl moieties are present in the polysaccharide.

After that, a periodate oxidation experiment was carried out with this polysaccharide fraction. The periodate-oxidized, reduced material of this fraction upon hydrolysis with TFA followed by GLC analysis showed the presence of 1,3,5,6-tetra-O-acetyl-2,4-di-Omethyl-D-glucitol only. No peaks corresponding to 1,5,6-tri- $O$-acetyl-2,3,4-tri- $O$-methylD-glucitol; and 1,5-di- $O$-acetyl-2,3,4,6-tetra- $O$-methyl-D-galactitol were observed during GLC analysis of periodate-oxidized, reduced, and methylated polysaccharides. These results indicate $(1 \rightarrow 3,6)$-linked D-glucopyranosyl moieties was present only. Thus, the 
periodate oxidation study confirms the mode of linkages of the sugar moieties present in the polysaccharide.

Along with these above chemical investigations, different $1 \mathrm{D}\left({ }^{1} \mathrm{H},{ }^{13} \mathrm{C}\right)$ and $2 \mathrm{D}$ NMR spectroscopic experiments (TOCSY, DQF-COSY, NOESY, ROESY, HMQC, and HMBC) were also performed with BJPS for the determination of the exact structure.

The ${ }^{1} \mathrm{H}$ NMR (500 MHz) spectrum (Fig. 3) at $27{ }^{\circ} \mathrm{C}$ showed three signals in the anomeric region at $\delta 5.11,4.97,4.51 \mathrm{ppm}$ in a ratio of nearly 1:1:2 but the expansion of the peak at $\delta 4.51 \mathrm{ppm}$ showed two overlapped signals at 4.51 and $4.50 \mathrm{ppm}$. All the ${ }^{1} \mathrm{H}$ signals were assigned using DQF-COSY and TOCSY NMR experiments. The four sugar moieties were designated as residues $\mathrm{A}, \mathrm{B}, \mathrm{C}$, and $\mathrm{D}$ according to their decreasing chemical shifts (Table 1) in the ${ }^{1} \mathrm{H}$ NMR spectrum.

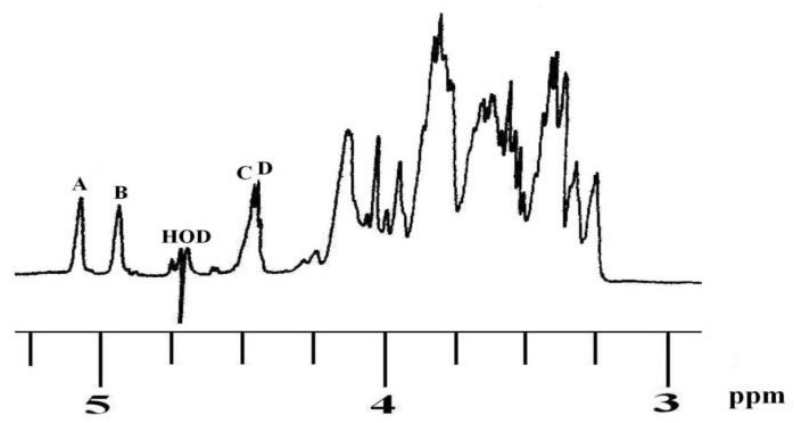

Fig. 3. ${ }^{1} \mathrm{H}$ NMR spectrum $\left(500 \mathrm{MHz}, \mathrm{D}_{2} \mathrm{O}, 27^{\circ} \mathrm{C}\right)$ of the polysaccharide (PS-I) isolated from $P$. sajor-caju (cv Black Japan).

Table 1. ${ }^{1} \mathrm{H} \mathrm{NMR}^{\mathrm{a}}$ data for the polysaccharide isolated from Pleurotus sajor-caju (cv Black Japan) in $\mathrm{D}_{2} \mathrm{O}$ at $27^{\circ} \mathrm{C}$.

\begin{tabular}{|c|c|c|c|c|c|c|}
\hline Glycosyl Residues & $\mathrm{H}-1$ & $\mathrm{H}-2$ & H-3 & H-4 & H-5 & H-6a, H-6b \\
\hline$\alpha-\mathrm{D}-\mathrm{Gal} p-(1 \rightarrow$ & 5.11 & 3.80 & 3.89 & 4.03 & 4.11 & $3.70^{\mathrm{c}}, 3.72^{\mathrm{d}}$ \\
\hline $\begin{array}{c}\rightarrow 6)-\alpha-\mathrm{D}-\mathrm{Glc} p-(1 \rightarrow \\
\mathbf{B}\end{array}$ & 4.97 & 3.82 & 3.66 & 3.76 & 3.93 & $3.88^{\mathrm{c}}, 4.19^{\mathrm{d}}$ \\
\hline $\begin{array}{c}\rightarrow 3,6)-\beta-\mathrm{D}-\mathrm{Glcp}(1 \rightarrow \\
\mathbf{C}\end{array}$ & 4.51 & 3.51 & 3.69 & 3.84 & 3.61 & $4.07^{\mathrm{c}}, 4.18^{\mathrm{d}}$ \\
\hline $\begin{array}{c}\rightarrow 6)-\beta-\mathrm{D}-\mathrm{Glc} p-(1 \rightarrow \\
\text { D }\end{array}$ & 4.50 & 3.30 & 3.42 & 3.46 & 3.34 & $3.73^{\mathrm{c}}, 4.17^{\mathrm{d}}$ \\
\hline
\end{tabular}

${ }^{a}$ Values of the ${ }^{1} \mathrm{H}$ chemical shifts were recorded with respect to the HOD signal fixed at $\delta 4.67 \mathrm{ppm}$ at $27^{\circ} \mathrm{C}$.

${ }^{\mathrm{c}, \mathrm{d}}$ Interchangeable.

In the ${ }^{13} \mathrm{C}$ NMR spectrum (Fig. 4 ) at $27^{\circ} \mathrm{C}$, four anomeric signals appeared at $\delta 103.4$, 98.2, and $98.0 \mathrm{ppm}$ (Table 2) in a ratio of 2:1:1, the peak at $\delta 103.4 \mathrm{ppm}$ corresponds to the anomeric carbon chemical shift for both the residue $\mathbf{C}$ and residue $\mathbf{D}$. All the ${ }^{13} \mathrm{C}$ signals were assigned using HMQC and HMBC NMR experiments. 


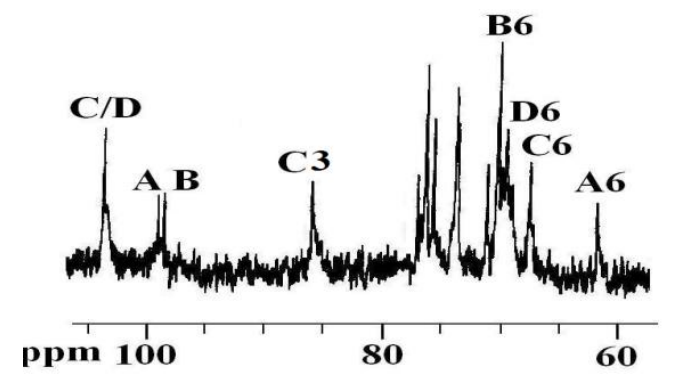

Fig. $4 .{ }^{13} \mathrm{C}$ NMR spectrum $\left(125 \mathrm{MHz}, \mathrm{D}_{2} \mathrm{O}, 2{ }^{\circ} \mathrm{C}\right)$ of the polysaccharide (PS-I) isolated from $P$. sajor-caju (cv Black Japan).

Table 2. The ${ }^{13} \mathrm{C} \mathrm{NMR}^{\mathrm{b}}$ chemical shifts for the polysaccharide isolated from Pleurotus sajor-caju (cv Black Japan) in $\mathrm{D}_{2} \mathrm{O}$ at $27^{\circ} \mathrm{C}$.

\begin{tabular}{|c|c|c|c|c|c|c|}
\hline Glycosyl Residues & $\mathrm{C}-1$ & $\mathrm{C}-2$ & $\mathrm{C}-3$ & $\mathrm{C}-4$ & $\mathrm{C}-5$ & $\mathrm{C}-6$ \\
\hline$\underset{\mathbf{A}}{\alpha-\mathrm{D}-\mathrm{Gal} p-(1 \rightarrow}$ & 98.2 & 69.5 & 69.9 & 69.9 & 70.8 & 61.4 \\
\hline $\begin{array}{c}\rightarrow 6)-\alpha-\mathrm{D}-\mathrm{Glc} p-(1 \rightarrow \\
\mathbf{B}\end{array}$ & 98.0 & 73.3 & 75.3 & 70.0 & 70.6 & 69.2 \\
\hline $\begin{array}{c}\rightarrow 3,6)-\beta-\mathrm{D}-\mathrm{Glc} p(1 \rightarrow \\
\mathbf{C}\end{array}$ & 103.4 & 73.4 & 85.2 & 68.7 & 69.9 & 67.5 \\
\hline $\begin{array}{c}\rightarrow 6)-\beta-\mathrm{D}-\mathrm{Glc} p-(1 \rightarrow \\
\text { D }\end{array}$ & 103.4 & 73.4 & 76.6 & 69.5 & 70.0 & 68.8 \\
\hline
\end{tabular}

${ }^{\mathrm{b}}$ Values of chemical shifts were recorded with reference to acetone as internal standard and fixed at $\delta 31.05 \mathrm{ppm}$ at $27^{\circ} \mathrm{C}$.

Residue A was assigned to the non-reducing-end D-galactosyl unit. The galacto configuration was assigned from the large ${ }^{3} \boldsymbol{J}_{2,3}$ couplings constant of $\sim 8 \mathrm{~Hz}$ and relatively small ${ }^{3} J_{3,4}$ couplings constant of $\sim 3 \mathrm{~Hz}$. The $\alpha$ configuration of residue $\mathbf{A}(\delta 5.11)$ was assigned from ${ }^{3} J_{1,2}$ coupling constant of $\sim 3 \mathrm{~Hz}$ and ${ }^{1} J_{\mathrm{C}, \mathrm{H}}$ of $\sim 170 \mathrm{~Hz}$. The carbon signal at $98.2 \mathrm{ppm}$ was assigned to $\mathrm{C}-1$ of residue A. The carbon signals from C-1 to C-6 of residue A correspond nearly to the standard values of methyl glycosides [40.41]. Thus considering the results of methylation analysis and NMR spectroscopy, it is concluded that residue $\mathbf{A}$ is an $\alpha$-linked, terminal D-galactopyranosyl moiety.

Residue $\mathbf{B}$ has an anomeric proton signal at $\delta 4.97 \mathrm{ppm}$, and the ${ }^{3} J_{1,2} \sim 3 \mathrm{~Hz},{ }^{1} J_{\mathrm{C}, \mathrm{H}}$ of $\sim 171 \mathrm{~Hz}$ indicate that it is an $\alpha$-linked moiety. Large coupling constant ${ }^{3} J_{2,3}$, and ${ }^{3} J_{3,4}$ $(\sim 10 \mathrm{~Hz})$ for residue B supports a D-glucosyl moiety. The carbon signal at $98.0 \mathrm{ppm}$ was assigned to $\mathrm{C}-1$ of residue $\mathbf{B}$. With respect to standard values [40.41] the downfield shift for C-6 (69.2 ppm) indicates that moiety $\mathbf{B}$ is linked at C-6. The other values for carbons correspond nearly to standard values. $\mathbf{B}$ is thus a $(1 \rightarrow 6)$-linked- $\alpha$-D-glucopyranosyl moiety.

Residue $\mathbf{C}$ has an anomeric proton signal at $\delta 4.51 \mathrm{ppm}$, and the ${ }^{3} J_{1,2} \sim 8 \mathrm{~Hz},{ }^{1} J_{\mathrm{C}, \mathrm{H}}$ of $\sim 160 \mathrm{~Hz}$ indicate that it is a $\beta$-linked moiety. Large coupling constant ${ }^{3} J_{2,3}$, and ${ }^{3} J_{3,4}(\sim 10$ $\mathrm{Hz}$ ) for residue $\mathbf{C}$, supports that it is a D-glucosyl moiety. Its anomeric carbon signal appears at $\delta 103.4 \mathrm{ppm}$. The downfield shift of C-3 ( $\delta 85.2 \mathrm{ppm})$ and for C-6 (67.5 ppm) 
with respect to standard values [40.41] indicates that moiety $\mathbf{C}$ is linked at C-3 and C-6. These observations indicate that $\mathbf{C}$ is 1,3,6-linked - $\beta$-D-glucopyranosyl moiety.

Residue $\mathbf{D}$ has an anomeric proton signal at $\delta 4.50 \mathrm{ppm}$, and the ${ }^{3} J_{1,2} \sim 8 \mathrm{~Hz},{ }^{1} J_{\mathrm{C}, \mathrm{H}}$ of $\sim 160 \mathrm{~Hz}$ indicate that it is a $\beta$-linked moiety. Large coupling constant ${ }^{3} J_{2,3}$, and ${ }^{3} J_{3,4}(\sim 10$ $\mathrm{Hz}$ ) for residue $\mathbf{D}$, supports that it is a D-glucosyl moiety. Its anomeric carbon signal appears at $\delta 103.4 \mathrm{ppm}$. With respect to standard values [40,41] the downfield shift for C$6(68.8 \mathrm{ppm})$ indicates that moiety $\mathbf{D}$ is also linked at $\mathbf{C}-6$. Thus it may be concluded that $\mathbf{D}$ is $(1 \rightarrow 6)$-linked- $\beta$-D-glucopyranosyl moiety.

To find the sequences of glycosyl residues of the polysaccharide, we examined the NMR of NOESY and ROESY (Fig. 5, Table 3) experiment followed by confirmation with HMBC experiment. Residue A has interresidue ROE contacts from $\mathrm{H}-1$ to $\mathrm{H}-6 \mathrm{a}$, and $\mathrm{H}-6 \mathrm{~b}$ of residue $\mathbf{C}$ in addition to intraresidue contacts to $\mathrm{H}-2$ and $\mathrm{H}-3$. This indicates that residue $\mathbf{A}$ is linked at the 6-position of residue $\mathbf{C}$, and the following sequence is established;

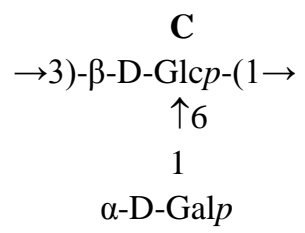

A

Residue $\mathbf{B}$ has an interresidue $\mathrm{ROE}$ contact from $\mathrm{H}-1$ to $\mathrm{H}-3$ of residue $\mathbf{C}$ in addition to intraresidue contacts to $\mathrm{H}-2, \mathrm{H}-3, \mathrm{H}-4, \mathrm{H}-6 \mathrm{a}$, and $\mathrm{H}-6 \mathrm{~b}$. This indicates that residue $\mathbf{B}$ is linked at the 3-position of residue $\mathbf{C}$, and the following sequence is established;

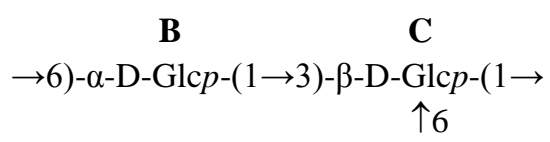

Residue $\mathbf{C}$ has interresidue ROE contacts from $\mathrm{H}-1$ to $\mathrm{H}-6 \mathrm{a}$ and $\mathrm{H}-6 \mathrm{~b}$ of residue $\mathbf{D}$ in addition to intraresidue contacts to $\mathrm{H}-4$ and $\mathrm{H}-5$. Hence, it can be concluded that residue $\mathbf{C}$ is linked to the 6-position of residue $\mathbf{D}$. Hence the following sequence is established;

$$
\begin{array}{cc}
\mathbf{C} & \mathbf{D} \\
\rightarrow 3)-\beta-D-G l c p-(1 \rightarrow 6)-\beta-D-G l c p-(1 \rightarrow \\
\uparrow 6
\end{array}
$$

Residue D has interresidue ROE contacts from $\mathrm{H}-1$ to $\mathrm{H}-6 \mathrm{a}$ and $\mathrm{H}-6 \mathrm{~b}$ of residue $\mathbf{B}$ in addition to intraresidue contacts to $\mathrm{H}-2, \mathrm{H}-3$, and $\mathrm{H}-4$, indicating that residue $\mathbf{D}$ is linked at the 6-position of residue $\mathbf{B}$. Therefore, the following sequence is established;

$$
\underset{\rightarrow 6)-\beta-D-G l c p-(1 \rightarrow 6)-\alpha-D-G l c p-(1 \rightarrow}{\text { D }}
$$

The above sequences of glycosyl residues of the polysaccharide were also determined from NOESY experiment. 
Since A, B, C, D are present in a molar ratio of $1: 1: 1: 1$, therefore, the repeating unit for polysaccharide is assigned as follows;

B $\rightarrow 6)-\alpha-\mathrm{D}-\mathrm{Glc} p-(1 \rightarrow 3)-\beta-\mathrm{D}-\mathrm{Glc} p-(1 \rightarrow 6)-\beta-\mathrm{D}-\mathrm{Glc} p-(1 \rightarrow$
6
$\uparrow$
1
$\alpha-\mathrm{D}-\mathrm{Gal} p$

A

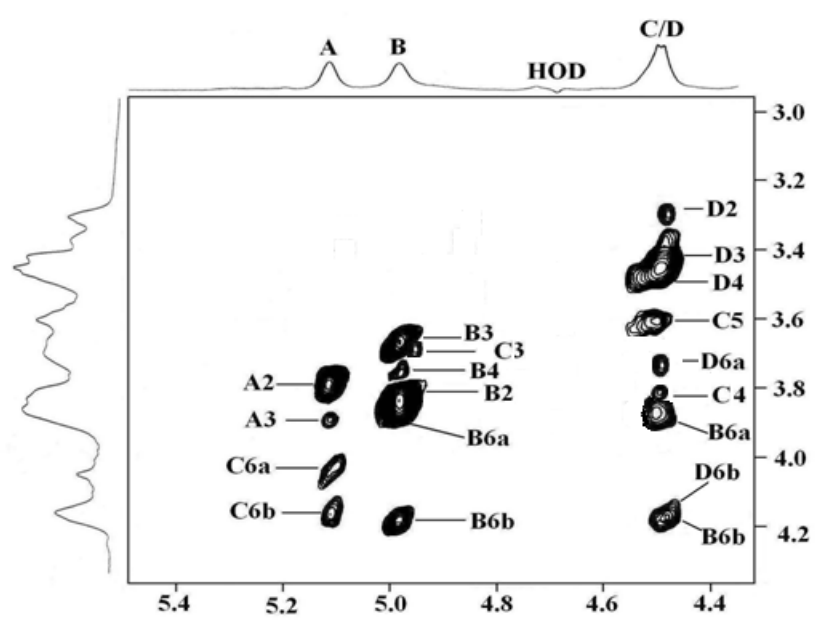

Fig. 5. The ROSEY spectra of the polysaccharide (PS-I) isolated from ROSEY mixing time was $300 \mathrm{~ms}$.

Table 3. ROESY data for the polysaccharide isolated from Pleurotus sajor-caju (cv Black Japan).

\begin{tabular}{|c|c|c|c|}
\hline \multicolumn{2}{|l|}{ Anomeric proton } & \multicolumn{2}{|c|}{ ROE contact to protons } \\
\hline Glycosyl residues & $\delta$ & $\delta$ & Residue/atoms \\
\hline$\alpha-\mathrm{D}-\mathrm{Gal} p-(1 \rightarrow$ & 5.11 & 4.07 & C H-6a \\
\hline \multirow[t]{3}{*}{$\mathbf{A}$} & & 4.18 & C H-6b \\
\hline & & 3.80 & A H-2 \\
\hline & & 3.89 & A H-3 \\
\hline$\rightarrow 6)-\alpha-\mathrm{D}-\mathrm{Glc} p-(1 \rightarrow$ & 4.97 & 3.69 & C H-3 \\
\hline \multirow[t]{5}{*}{ B } & & 3.82 & B H-2 \\
\hline & & 3.66 & B H-3 \\
\hline & & 3.76 & B H-4 \\
\hline & & 3.88 & B H-6а \\
\hline & & 4.19 & B $\mathrm{H}-6 \mathrm{~b}$ \\
\hline$\rightarrow 3,6)-\beta-D-G l c p-(1 \rightarrow$ & 4.51 & 3.73 & D H-6a \\
\hline \multirow[t]{3}{*}{$\mathbf{C}$} & & 4.17 & D H-6b \\
\hline & & 3.84 & C H-4 \\
\hline & & 3.61 & C H-5 \\
\hline
\end{tabular}




\begin{tabular}{|c|c|c|c|}
\hline $\begin{array}{c}\rightarrow 6)-\beta-\mathrm{D}-\mathrm{Glc} p-(1 \rightarrow \\
\text { D }\end{array}$ & 4.50 & $\begin{array}{l}3.88 \\
4.19 \\
3.30 \\
3.42 \\
3.46 \\
\end{array}$ & $\begin{array}{l}\text { B H-6a } \\
\text { B H-6b } \\
\text { D H-2 } \\
\text { D H-3 } \\
\text { D H-4 }\end{array}$ \\
\hline
\end{tabular}

The cross-peaks of both anomeric protons and carbons from HMBC experiment (Table 4, Fig. 6) of each sugar moieties were examined. Both intra- and inter-residual connectivities were observed in the HMBC experiment. Cross peaks were found between $\mathrm{H}-1$ of residue $\mathbf{A}(\delta 5.11)$ with $\mathbf{C}-6$ of residue $\mathbf{C}(\mathbf{A ~ H}-1, \mathbf{C ~ C}-6)$; $\mathbf{C}-1$ of residue $\mathbf{A}(\delta$ 98.2) and H-6a, H-6b of residue $\mathbf{C}$ (A C-1, C H-6a; A C-1, C H-6b), with other intraresidual coupling between $\mathrm{H}-1$ of residue $\mathbf{A}$ with its $\mathrm{C}-3$ atom. Cross peaks were also observed between $\mathrm{H}-1$ of residue $\mathbf{B}(\delta 4.97)$ with $\mathrm{C}-3$ of residue $\mathbf{C}$ (B H-1, C C-3); C-1 of residue $\mathbf{B}$ ( $\delta$ 98.0) and $\mathrm{H}-3$ of residue $\mathbf{C}(\mathbf{B ~ C}-1, \mathbf{C ~ H}-3)$ with another intraresidual coupling between $\mathrm{H}-1$ of residue $\mathbf{B}$ with its $\mathrm{C}-5$ atom. Cross peaks between $\mathrm{H}-1$ of residue $\mathbf{C}(\delta 4.51)$ with C-6 of residue D (C H-1, D C-6); C-1 of residue $\mathbf{C}(\delta 103.4)$ and H-6a, H-6b of residue D (C C-1, D H-6a; C C-1, D H-6b) with another intraresidual coupling between C-1 of residue $\mathbf{C}$ with its $\mathrm{H}-2$ atom were observed. Similarly, cross-peaks were found between $\mathrm{H}$ 1 of residue $\mathbf{D}(\delta 4.50)$ with C-6 of residue $\mathbf{B}$ (D H-1, B C-6); C-1 of residue $\mathbf{D}(\delta 103.4)$ and H-6a, H-6b of residue B (D C-1, B H-6a; D C-1, B H-6b) with another intraresidual coupling between $\mathrm{C}-1$ of residue $\mathbf{D}$ with its $\mathrm{H}-2, \mathrm{H}-3$, and $\mathrm{H}-5$ atoms. The appearance of these cross-peaks in the HMBC spectrum firmly supports the presence of a tetrasaccharide repeating unit in this polysaccharide.

Thus, based on all these chemical and spectroscopic evidence, the structure of the repeating unit of the polysaccharide is established as:

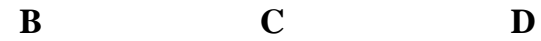

$$
\begin{gathered}
\rightarrow 6)-\alpha-\mathrm{D}-\mathrm{Glc} p-(1 \rightarrow 3)-\beta-\mathrm{D}-\mathrm{Glc} p-(1 \rightarrow 6)-\beta-\mathrm{D}-\mathrm{Glc} p-(1 \rightarrow \\
6 \\
\uparrow \\
1 \\
\alpha-\mathrm{D}-\mathrm{Gal} p
\end{gathered}
$$

\begin{tabular}{|c|c|c|c|c|c|}
\hline \multirow[t]{2}{*}{ Residue } & \multirow[t]{2}{*}{ Sugar linkage } & \multirow{2}{*}{$\begin{array}{l}\mathrm{H}-1 / \mathrm{C}-1 \\
\delta_{\mathrm{H}} / \delta_{\mathrm{C}}\end{array}$} & \multicolumn{3}{|c|}{ Observed connectivities } \\
\hline & & & $\delta_{\mathrm{H}} / \delta_{\mathrm{C}}$ & Residue & Atom \\
\hline \multirow[t]{4}{*}{$\mathbf{A}$} & $\alpha$-D-Gal $p-(1 \rightarrow$ & 5.11 & 67.5 & C & C-6 \\
\hline & & & 69.9 & $\mathbf{A}$ & $\mathrm{C}-3$ \\
\hline & & 98.2 & 4.07 & C & H-6a \\
\hline & & & 4.18 & $\mathbf{C}$ & $\mathrm{H}-6 \mathrm{~b}$ \\
\hline \multirow[t]{3}{*}{ B } & $\rightarrow 6)-\alpha-D-G l c p-(1 \rightarrow$ & 4.97 & 85.2 & $\mathbf{C}$ & $\mathrm{C}-3$ \\
\hline & & & 70.6 & B & C-5 \\
\hline & & 98.0 & 3.69 & C & $\mathrm{H}-3$ \\
\hline
\end{tabular}

A

Table 4. The significant ${ }^{3} J_{\mathrm{H}, \mathrm{C}}$ connectivities were observed in an HMBC spectrum for the anomeric protons/carbons of the sugar residues of the polysaccharide of Pleurotus sajor-caju (cv Black Japan). 


\begin{tabular}{|c|c|c|c|c|c|}
\hline \multirow[t]{4}{*}{$\mathbf{C}$} & $\rightarrow 3,6)-\beta$-D-Glc $p$ - $(1 \rightarrow$ & 4.51 & 68.8 & $\mathbf{D}$ & C-6 \\
\hline & & 103.4 & 3.73 & D & $\mathrm{H}-6 \mathrm{a}$ \\
\hline & & & 4.17 & D & $H-6 b$ \\
\hline & & & 3.51 & C & $\mathrm{H}-2$ \\
\hline \multirow[t]{6}{*}{ D } & $\rightarrow 6)-\beta-D-G l c p-(1 \rightarrow$ & 4.50 & 69.2 & B & $\mathrm{C}-6$ \\
\hline & & 103.4 & 3.88 & B & H-6a \\
\hline & & & 4.19 & B & $H-6 b$ \\
\hline & & & 3.30 & D & $\mathrm{H}-2$ \\
\hline & & & 3.42 & D & $\mathrm{H}-3$ \\
\hline & & & 3.34 & D & H-5 \\
\hline
\end{tabular}

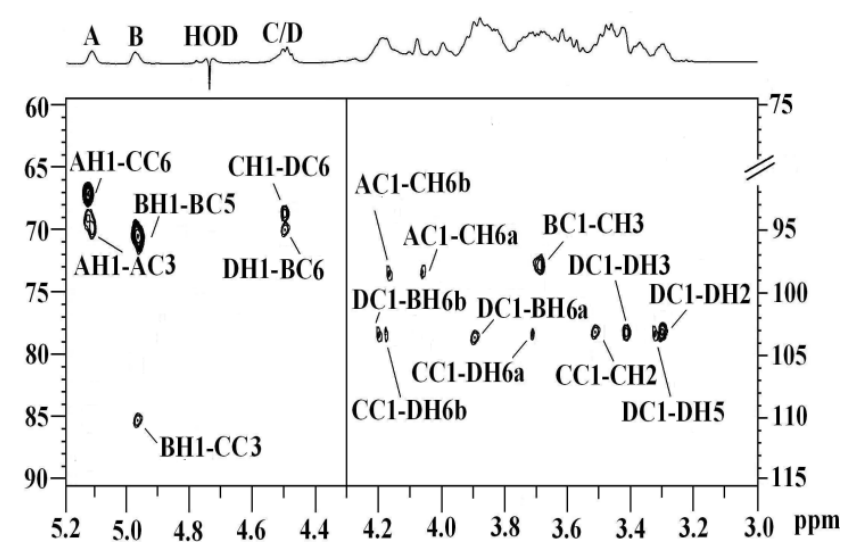

Fig. 6. HMBC spectrum of polysaccharide (PS-I) isolated from Pleurotus sajor-caju (cv Black Japan). The delay time in the HMBC experiment was $80 \mathrm{~ms}$.

\subsection{Characterization of PS-II}

On acid hydrolysis followed by GLC analysis showed that PS-II was pure glucans. The molecular weight of the PS-II was estimated from a calibration curve prepared with standard dextran as $2.60 \times 10^{5} \mathrm{Da}$. This glucan was then separately methylated by Ciucanu and Kerek method, followed by hydrolysis and alditol acetate preparation. The alditol acetates of this glucan were then analyzed by GLC-MS using HP-5 fused-silica capillary column and revealed 1, 3, 5-tri- $O$-acetyl-2, 4, 6-tri- $O$-methyl-glucitol only. These results indicated that the glucans were $(1 \rightarrow 3)$-linked.

The 125-MHz ${ }^{13} \mathrm{C}$ NMR spectrum at $27{ }^{\circ} \mathrm{C}$ (Fig. 7, Table 5) of PS-II showed six signals. The $\beta$ conformation of the D-glucosyl residue was evidenced by the presence of an anomeric peak at $\delta 103.8 \mathrm{ppm}$. The signal at $\delta 87.0 \mathrm{ppm}$ was assigned to $\mathrm{C}-3$ of a $(1 \rightarrow 3)-\beta$-D-glucosyl residue. The downfield shift of C-3 by $\delta 10.2 \mathrm{ppm}$ was due to the $\alpha$ effect of glycosylation. From the above experimental evidence, it was thus concluded that PS-II was a glucan composed of $(1 \rightarrow 3)$-linked $\beta$-D-glucopyranosyl repeating unit as; 


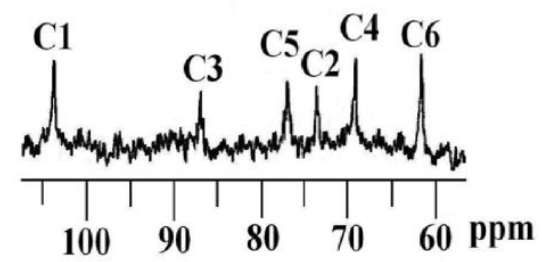

Fig. 7. ${ }^{13} \mathrm{C}$ NMR spectrum $\left(125 \mathrm{MHz}, \mathrm{Me}_{2} \mathrm{SO}-\mathrm{d}_{6}, 27{ }^{\circ} \mathrm{C}\right)$ of the polysaccharid (PS-II) isolated from P. sajor-caju (cv Black Japan).

Table 5. The chemical shifts in the ${ }^{13} \mathrm{C}$ NMR spectrum of PS-II isolated from Pleurotus sajor- caju (cv Black Japan) in $\mathrm{Me}_{2} \mathrm{SO}-\mathrm{d}_{6}$ at $27^{\circ} \mathrm{C}$.

\begin{tabular}{lrlllll}
\hline Sugar Residue & C-1 & C-2 & C-3 & C-4 & C-5 & C-6 \\
\begin{tabular}{c}
$\rightarrow 3)-\begin{array}{c}\beta-D-G l c p-(1 \rightarrow \\
\text { PS-II }\end{array}$ \\
\hline
\end{tabular} & 103.8 & 73.7 & 87.0 & 69.2 & 77.1 & 61.7 \\
\hline
\end{tabular}

\subsection{Test of biological activity}

Macrophage activation of the polysaccharide (PS-I) was observed in vitro. Upon treatment with different concentrations of the polysaccharide, an enhanced NO was observed in a dose-dependent manner with optimum production of $8.5 \mu \mathrm{M}$ NO per $5 \times 10^{5}$ macrophages at $80 \mu \mathrm{g} / \mathrm{mL}$ of the polysaccharide (Fig. 8). A similar kind of material like lentinan (a $\beta$ glucan) inhibits tumor growth by stimulating the immune system [26] through activation of macrophages, T-helper, NK, and other cells.

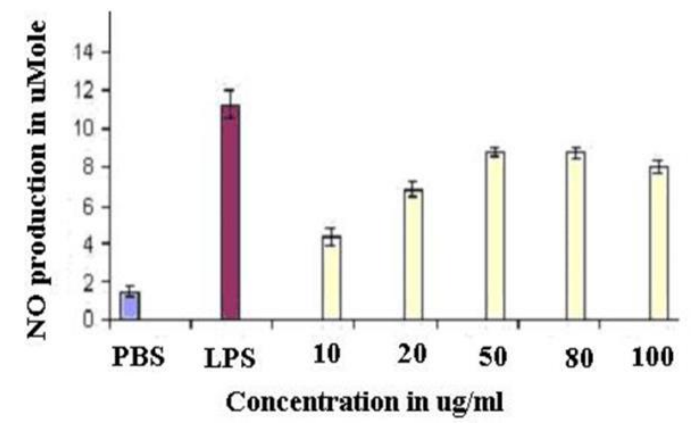

Fig. 8. In vitro activation of peritoneal macrophage stimulated with different concentrations of the polysaccharide in terms of NO production.

The splenocyte and thymocytes activation tests were carried out in mouse cell culture medium with the polysaccharide by the MTT [3-(4,5-dimethylthiazol-2-yl)-2,5diphenyltetrazolium bromide] method. The proliferation of splenocytes and thymocytes is an indicator of immune activation. The polysaccharide was tested to proliferate 
splenocytes and thymocytes, as shown in Figs. 9.(A) and 9 (B). At $20 \mu \mathrm{g} / \mathrm{mL}$ of the polysaccharide, the splenocyte proliferation index was maximum compared to other concentrations. $20 \mu \mathrm{g} / \mathrm{mL}$ of the polysaccharide can be considered efficient splenocyte proliferators, whereas $20 \mu \mathrm{g} / \mathrm{mL}$ of that sample shows the maximum effect on thymocyte proliferation. The splenocyte proliferation index (SPI) as compared to PBS (Phosphate Buffer Solution) control was close to 1 or below, which indicates a low stimulatory effect on the immune system. It is noteworthy to mention that several mushroom polysaccharides $[13,14$,$] have also shown a similar kind of splenocyte activation.$

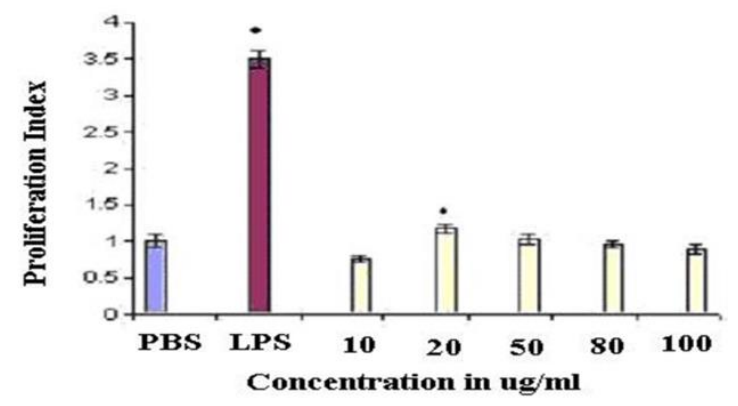

Fig. 9A. Effect of different of the polysaccharide on splenocyte (A) proliferation (*Significant compared to the PBS control).

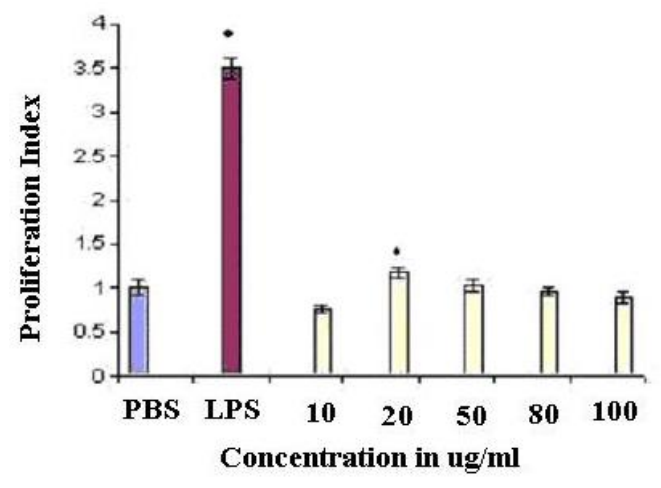

Fig. 9B. Effect of different of the polysaccharide on thymocyte (B) proliferation (*Significant compared to the PBS control).

\section{Conclusion}

We are reporting that the polysaccharide (PS-I) isolation of alkaline extract of edible mushroom of Pleurotus sajor-caju (cv Black Japan) are biologically active materials for the above experimental data. Moreover, we found that the water extracts of polysaccharides isolated from this edible mushroom are different structural moieties from the alkaline extract even though both polysaccharides contain the same sugar moieties. 
And also, we conclude that an insoluble glucan (PS-II) was also found from the alkaline extract of this edible mushroom.

\section{Acknowledgments}

The author is very grateful to S. Roy, Director, IICB, A. K. Sen (Jr.), IICB, and S. Lahiri, IACS, Kolkatta, for providing instrumental facilities. B. Majumder of Bose Institute, Kolkatta, is acknowledged for recording the NMR spectra.

\section{References}

1. Y. Dong and J. Xi, The Edible Mushrooms in China (China Tourist Publishing House: Beijing, 1988), Pp. 202-216.

2. C. Zhuang, T. Mizuno, A. Shimada, H. Ito, C. Suzuki, Y. Mayuzumi, H. Okamoto, Y. Ma, and J. Li, Biosci. Biotechnol. Biochem. 57, 901 (1993). https://doi.org/10.1271/bbb.57.901

3. D. M. Soden and A. D. W. Dobson, Microbiology 147, 1755 (2001). https://doi.org/10.1099/00221287-147-7-1755

4. D. M. Soden, J. P. Callaghan, and A. D. W. Dobson, Microbiology 148, 4003 (2002). https://doi.org/10.1099/00221287-148-12-4003

5. Y. Yoshioko, R. Tabeta, H. Saito, N. Uehara, and F. Fukuoka, Carbohydr. Res. 140, 93 (1985). https://doi.org/10.1016/0008-6215(85)85052-7

6. H. J. Mrjana, J. Dragica, M. S. Jelena, and P. Ljiljana, J. Serb. Chem. Soc. 53, 225 (1988).

7. J. Zhang, G. Wang, H. Li, C. Zhuang, T. Mizumo, H. Ito, C. Suzuki, H. Okamoto, and J. Li, Biosci. Biotechnol. Biochem. 58, 1195 (1994). https://doi.org/10.1271/bbb.58.1195

8. D. Rout, S. Mondal, I. Chakraborty, M. Pramanik, and S. S. Islam, Med. Chem. Res. 13, 509 (2004). https://doi.org/10.1007/s00044-004-0050-6

9. D. Rout, S. Mondal, I. Chakraborty, M. Pramanik, and S. S. Islam, Carbohydr. Res. 340, 2533 (2005). https://doi.org/10.1016/j.carres.2005.08.006

10. P. Khanna and H. S. Garcha, Mushroom Sci. 11, 561 (1981). https://doi.org/10.1016/j.carres.2007.08.012

11. J. Eder and A.Wuensch, Chem. Mikrobiol. Technol. Lebensm. 13, 25 (1991).

12. Y. J. Kwon and T. B. Uhny, Hanguk Yongyang Siklyong Hakhoechi. 13, 175 (1984).

13. D. Rout, S. Mondal, I. Chakraborty, and S. S. Islam, Carbohydr. Res. 341, 995 (2006). https://doi.org/10.1016/j.carres.2006.02.026

14. D. Rout, S. Mondal, I. Chakraborty, and S. S. Islam, Carbohydr. Res. 343, 982 (2008). https://doi.org/10.1016/j.carres.2006.02.026

15. D. Knop, O. Yarden, and Y. Hadar, Appl. Microbiol. Biotechnol. 99, 1025 (2015). https://doi.org/10.1007/s00253-014-6256-8

16. J. Raman, K. Y. Jang. Y.L. Oh, M. Oh, J. H. Im, H. Lakshmanan, and V. Sabaratnam, Mycobiology 49, 1 (2020). https://doi.org/10.1080/12298093.2020.1835142

17. H. Sardar, M. A. Ali, M. A. Anjum, F. Nawaz, S. Hussain, S. Naz, and S. M. Karimi, Sci. Hort. 225, 327 (2017). https://doi.org/10.1016/j.scienta.2017.07.010

18. M. Ritota and P. Manzi, Sustainability. 11(18), 5049 (2019). https://doi.org/10.3390/su11185049

19. A. Gutirrez, A. Prieto, and A. T. Martı'nez, Carbohydr. Res. 281, 143 (1996). https://doi.org/10.1016/0008-6215(95)00342-8

20. I. S. Assis, M. B. Chaves, M. L. L. Silveira, R. M. M. Gern, E. Wisbeck, A. F. Junior, and S. A. Furlan, J. Med. Food 16, 1004 (2013). https://doi.org/10.1089/jmf.2012.0267

21. M. Arisoy, Bull. Environ. Contamin. Toxicol. 60, 872 (1998).

22. S. F. Musa, S. Yeat, Z. Mohd, Y. M. Tabana, A. Ahmed, E. Ouweini, V. Lim, C. Keong, and D. Sandai, J. Sci. Food Agric. 98, 1197 (2018). https://doi.org/10.1002/jsfa.8573 
23. V. K. Chaturvedi, N. Yadav, N. K. Rai, N. H. A. Ellah, R. A. Bohara, I. F. Rehan, N. Marraiki, G. E. S. Batiha, H. F. Hetta, and M. P. Singh, Molecules 25, 3091 (2020). https://doi.org/10.3390/molecules25133091

24. M. Pramanik, I. Chakraborty, S. Mondal, and S. S. Islam, Carbohydr. Res. 342, 2670 (2007). https://doi.org/10.1016/j.carres.2007.08.012

25. M. Pramanik, S. Mondal, I. Chakraborty, D. Rout, and S. S. Islam, Carbohydr. Res. 340, 629 (2005). https://doi.org/10.1016/j.carres.2004.12.032

26. S. K. Roy, D. Maiti, S. Mondol, D. Das, and S. S. Islam, Carbohydr. Res. 343, 1108 (2008). https://doi.org/10.1016/j.carres.2008.02.015

27. W. S. York, A. K. Darvill, M. McNeil, T. T. Stevenson, and P. Albersheim, Methods Enzymol. 118, 33 (1985). https://doi.org/10.1016/0076-6879(86)18062-1

28. I. Ciucanu and F. Kerek, Carbohydr. Res. 131, 209 (1984). https://doi.org/10.1016/0008-6215(84)85242-8

29. G. J. Gerwig, J. P. Kamerling, and J. F. G. Vliegenthart, Carbohydr. Res. 62, 349 (1978). https://doi.org/10.1016/S0008-6215(00)80881-2

30. C. Hara, T. Kiho, Y. Tanaka, and S. Ukai, Carbohydr. Res. 110, 77 (1982). https://doi.org/10.1016/0008-6215(82)85027-1

31. M. T. D. Chasco, M. A. Rodriguez-Carvajal, P. T. Mateo, G. Franko-Rodriguez, J. L. Espartero, A. I. Iribas, and A. M. Gil-Serrano, Carbohydr. Res. 303, 453 (1997). https://doi.org/10.1016/S0008-6215(97)00192-4

32. K. Hård, G. V. Zadelhoff, P. Moonen, J. P. Kamerling, and J. F. G. Vliegenthart, Eur. J. Biochem. 209, 895 (1992). https://doi.org/10.1111/j.1432-1033.1992.tb17362.x

33. N. Ohno, K. Saito, J. Nemoto, S. Kaneko, Y. Adachi, M. Nishijima, T. Miyazaki, and T. Yadomae, Biol. Pharm. Bull. 16, 414 (1993). https://doi.org/10.1248/bpb.16.414

34. N. Ohno, T. Hasimato, Y. Adachi, and T. Yadomae, Immunol. Lett. 52, 1 (1992). https://doi.org/10.1016/S0165-2478(96)02639-9

35. I. Sarangi, D. Ghosh, S. K. Bhutia, S. K. Mallick, and T. K. Maiti, Int. Immunopharmacol. 6, 1287 (2006). https://doi.org/10.1016/j.intimp.2006.04.002

36. S. Maiti, S. K. Bhutia, S. K. Mallick, A. Kumar, N. Khadgi, and T. K. Maiti, Environmental Toxicol. pharmacol. 6, 1287 (2006). https://doi.org/10.1016/j.etap.2008.03.009

37. G. Chihara, Mushroom Sci. 9, 797 (1978).

38. S. Mondal, I. Chakraborty, and D. Rout, Carbohydr. Res. 341, 878 (2006). https://doi.org/10.1016/j.carres.2006.02.004

39. L. C. Green, D. A. Wagner, J. Glogowski, P. L. Skipper, J. S. Wishnok, and S. R. Tannenbaum, Anal. Biochem. 126, 131 (1982). https://doi.org/10.1016/0003-2697(82)90118-X

40. P. K. Agrawal, Phytochem. 31, 3307 (1992). https://doi.org/10.1016/0031-9422(92)83678-R

41. R. Rinaudo and M. Vincendon, Carbohydr. Polym. 2, 135 (1982). https://doi.org/10.1016/0144-8617(82)90059-5 